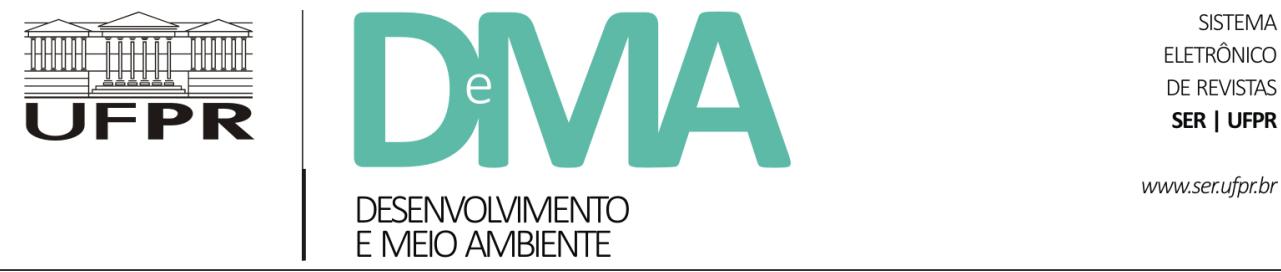

\title{
O Santuário Ecológico de Ilhabela como área marinha protegida a ser incorporada ao SNUC: panorama atual e próximos passos
}

\section{The Ilhabela Ecological Sanctuary as a Marine Protected Area to be Incorporate to SNUC: Current Overview and Next Steps}

\author{
Maila Paisano Guilhon e SÁ ${ }^{*}$, Zysman NEIMAN ${ }^{1}$, Ana Cristina Vigliar BONDIOLI² \\ ${ }^{1}$ Programa de Pós-graduação em Análise Ambiental Integrada, Universidade Federal de São Paulo (UNIFESP), Diadema, SP, Brasil. \\ ${ }^{2}$ Núcleo de Pesquisas - NUPE, Centro Universitário ENIAC, Guarulhos, SP, Brasil. \\ *E-mail de contato: ma_guilhon@hotmail.com
}

Artigo recebido em 5 de dezembro de 2016, versão final aceita em 3 de julho de 2017.

RESUMO: O Santuário Ecológico de Ilhabela foi criado mediante decreto municipal em 1992, apresentando desde aquela época evidências de degradação ambiental devido a atividades humanas. Com a criação do Sistema Nacional de Unidades de Conservação, a categoria "Santuário Ecológico" passou a não ter mais validade, havendo necessidade de recategorização a uma das categorias presentes na Lei. Ilhabela é um município que tem como principal fonte de renda atividades relacionadas ao turismo, que, se mal planejadas, podem levar a impactos sociais, ambientais e econômicos. A região do Canal de São Sebastião em que o Santuário está localizado possui rica fauna marinha, mas também sofre grande pressão antrópica, fator que pode colocar em risco, inclusive, a saúde e bem-estar de moradores, turistas e da fauna marinha local. Nos últimos anos, grupos vêm buscando apresentar dados que justifiquem a proposta de recategorização da área, até o presente momento sem sucesso. Este artigo tem por objetivo contextualizar a atual situação do Santuário Ecológico de Ilhabela, apresentar subsídios que justifiquem sua recategorização e indicar caminhos para a continuidade do processo.

Palavras-chave: Unidade de Conservação; área marinha protegida; Ilhabela; Santuário Ecológico; turismo.

ABSTRACT: Ilhabela Ecological Sanctuary is a marine protected area created through a municipal decree in 1992. Since that time it was possible to identify evidences of environmental degradation caused by human activities in the area. According to the most recent law of protected areas in Brazil (SNUC), the category Ecological Sanctuary is no longer valid, demanding the area to be reclassified within the new law. The tourism and correlated services are the main sources of income for Ilhabela. However, if poorly planned, tourism 
activities can lead to social, environmental and economic impacts. The Ecological Sanctuary is placed in a region that houses a rich marine fauna, the São Sebastião Channel. This area, however, also suffers with great anthropic pressure, which may endanger the health and well-being of residents, tourists and local marine fauna. In the last years groups have presented data to attempt the reclassification of the Sanctuary, with no success to the present moment. This article aims to contextualize the current situation of Ilhabela Ecological Sanctuary, present subsidies that justify its reclassification and indicate ways to continue the process.

Keywords: Conservation Units; marine protected area; Ilhabela; Ecological Sanctuary; tourism.

\section{Introdução}

Área protegida, segundo a União Internacional para Conservação da Natureza (UICN), pode ser descrita como "uma área com limites geográficos definidos e reconhecidos, cujo intuito, manejo e gestão buscam atingir a conservação da natureza, de seus serviços ecossistêmicos e valores culturais associados de forma duradoura, por meios legais ou outros meios efetivos" (Dudley, 2008).

Nessa mesma linha, a Convenção da Diversidade Biológica, o instrumento internacional mais importante no que diz respeito às áreas protegidas, a descreve como "área definida geograficamente que é destinada, ou regulamentada, e administrada para alcançar objetivos especificos de conservação" (MMA, 2000). Ainda, sob uma perspectiva antropológica, podem ser interpretadas como: "uma resposta cultural para ameaças percebidas à natureza" (Mcneely, 1998 apud Chape et al., 2005).

No Brasil, as áreas protegidas (terrestres ou marinhas) recebem a nomenclatura de Unidades de Conservação (UCs) (Schiavetti et al., 2013) e são definidas como "espaço territorial e seus recursos ambientais, incluindo as águas jurisdicionais, com características naturais relevantes, legalmente instituído pelo Poder Público, com objetivos de conservação e limites definidos, sob regime especial de administração, ao qual se aplicam garantias adequadas de proteção" (MMA, 2011a).

Atualmente, encontra-se em vigor no Brasil a Lei $\mathrm{n}^{\circ}$ 9985, de 18 de julho de 2000, que institui o Sistema Nacional de Unidades de Conservação (SNUC). Essa legislação divide as categorias de UCs em dois possíveis grupos: Proteção Integral e Uso Sustentável.

O objetivo das Unidades de Proteção Integral é "preservar a natureza, sendo admitido apenas o uso indireto de seus recursos naturais" (art. $7^{\circ}$, $\S 1^{\circ}$ ) e apresenta as seguintes categorias: Estação Ecológica, Reserva Biológica, Parque Nacional, Monumento Natural e Refúgio de Vida Silvestre. Já o grupo de Uso Sustentável é formado pelas seguintes categorias: Área de Proteção Ambiental, Área de Relevante Interesse Ecológico, Floresta Nacional, Reserva Extrativista, Reserva de Fauna, Reserva de Desenvolvimento Sustentável e Reserva Particular do Patrimônio Natural. Este segundo grupo tem por finalidade "compatibilizar a conservação da natureza com o uso sustentável de parcela de seus recursos naturais" (art. $7^{\circ}, \S 2^{\circ}$ ) e, portanto, suas categorias são menos restritivas que as de Proteção Integral.

A lei representa avanços e passou a prever a participação da população no ato da criação da 
Unidade, nos conselhos de gestão e na elaboração de Planos de Manejo. Além disso, surgem como outros pontos positivos a definição de categorias de manejo mais flexíveis frente às demandas sociais, a presença de instrumentos como corredores ecológicos e mosaicos e a garantia de que os recursos gerados nas UCs sejam aplicados nas mesmas (Medeiros, 2006; MMA, 2011b).

O número de UCs e a extensão por elas protegidas vinha crescendo de forma acelerada nas últimas décadas no Brasil (Medeiros \& Young, 2011; ISA, 2016). Esse crescimento foi fundamental para garantir a conservação da biodiversidade, principalmente em um país diverso como o Brasil (Drummond et al., 2011). As UCs, no entanto, possuem alguns problemas associados ao seu funcionamento, como: a falta de recursos financeiros, que muitas vezes as mantém somente "no papel"; a capacitação de profissionais; regularização fundiária; fiscalização; promoção da visitação, da pesquisa e da educação ambiental; e o apoio de setores da sociedade (Drummond et al., 2011; Prates \& Sousa, 2014).

Apesar dos avanços representados pela criação do SNUC, o histórico de criação de UCs no Brasil vem se desenvolvendo em meio a um cenário de conflitos, especialmente junto a comunidades tradicionais. Para Diegues (1998), a criação das UCs envolveu dificuldades de ordem econômica, social, e principalmente política, e ocasionou graves conflitos entre essas populações e os gestores, pois as áreas protegidas foram criadas tendo somente como característica a reserva de recursos. Foram desconsideradas as interações entre as populações e o meio ambiente, mesmo as populações tidas como tradicionais, e na sua criação não houve nenhuma participação da população que nelas residia, ou que utilizava os seus recursos como meio de subsistência (Diegues, 2004). Os formuladores das políticas ambientais defendiam que, para haver de fato a conservação dos recursos naturais, era necessária a exclusão das populações humanas destas áreas (Diegues, 2001).

Outro fator é também a inexistência de estratégias de integração das UCs à dinâmica local e às questões globais, ligadas a acordos internacionais. Neste sentido, surgem problemas como utilização de terras para diversas formas de uso (cultivo, caça, extrativismo, exploração, assentamentos, etc.) e a exploração da biodiversidade com fins industriais ou ligados à biotecnologia (Medeiros et al., 2004). Assim, mesmo diante dos avanços alcançados pelo país na criação de UCs em seu território, permanece o desafio de desenvolver um sistema de planejamento e gestão efetivo que garanta representatividade ecológica e conectividade entre as áreas (Prates \& Souza, 2014).

Dentre os fatores mais importantes para a manutenção e sucesso dos objetivos das UCs está a necessidade de um planejamento abrangente e integrado, baseado em uma visão de sistema que possibilite o monitoramento das ações, dificuldades, ameaças, avanços e efetividade da sua gestão (Padovan, 2002; Drummond et al., 2011).

As UCs vêm ganhando força nos últimos anos em termos de pesquisa e esforços voltados para a criação dessas áreas. Apesar disso, no Brasil existe uma disparidade quanto à proteção conferida a áreas terrestres e marinhas. A preocupação com o estabelecimento de Áreas Marinhas Protegidas (AMPs) só se tornou evidente nos últimos anos (Prates, 2014), fato que pode ser constatado por dados apresentados pelo MMA em 2014, quando apenas $1,5 \%$ da região marinha do país era constituída por 
AMPs, enquanto o ambiente continental apresentava aproximadamente $17 \%$ de área protegida (Prates \& Souza, 2014).

Dentre os benefícios trazidos pelas AMPs, encontram-se a proteção da biodiversidade e de habitats sensíveis, a promoção de refúgio para espécies intensamente exploradas, a proteção de espécies ameaçadas, o aumento da produtividade pesqueira, o sequestro de carbono, a redução do impacto do turismo e de outras atividades humanas, a geração de empregos e o estímulo do comércio e dos serviços culturais (Reuchlin-Hugenholtz \& Mckenzie, 2015).

No contexto da $10^{\mathrm{a}}$ Convenção das Partes, realizada em Nagoya, Japão, no ano de 2010, foram estabelecidas 20 metas a serem cumpridas até o ano de 2020 para conter a perda de biodiversidade (Weigand Junior et al., 2011). Nomeadas "Metas de Aichi”, essas diretrizes indicam compromissos assumidos pelas Partes que deverão ser definidos de acordo com as prioridades e capacidades nacionais (MMA, 2013). Em conformidade com o objetivo estratégico "Melhorar a situação da biodiversidade protegendo ecossistemas, espécies e diversidade genética", a Meta 11 dispõe o seguinte:

Até 2020 , pelo menos $17 \%$ das áreas terrestres e de águas continentais e $\mathbf{1 0} \%$ de áreas marinhas e costeiras, especialmente áreas de especial importância para a biodiversidade e serviços ecossistêmicos, terão sido conservadas por meio de sistemas de áreas protegidas, geridas de maneira efetiva e equitativa, ecologicamente representativas e satisfatoriamente interligadas e por outras medidas espaciais de conservação, e integradas em paisagens terrestres e marinhas mais amplas (MMA, 2013, grifo nosso).
Seguindo o texto da Meta 11, o Brasil praticamente já atingiu o disposto para a área terrestre. No entanto, quanto aos ambientes marinhos e costeiros, o país ainda está distante da meta, tendo atingido apenas $15 \%$ do total previsto (Prates \& Souza, 2014).

Além da criação de novas áreas protegidas no ambiente marinho, outra solução possível para aproximar o Brasil do cumprimento da Meta 11 seria a recategorização de áreas marinhas protegidas já existentes. Trata-se de áreas criadas anteriormente ao estabelecimento do SNUC e que, por não possuírem categorias compatíveis com a nova legislação, passaram a não ser consideradas oficialmente como protegidas.

Este é o caso do Santuário Ecológico de Ilhabela (SEI), uma área marinha protegida, criada através do Decreto Municipal no 953/92 e localizada no canal de São Sebastião. O SEI não é considerado uma UC, uma vez que sua nomenclatura não consta como categoria do SNUC. A região encontra-se, portanto, legalmente desprotegida, sem que haja qualquer fiscalização ou monitoramento das atividades que ocorrem na área (Sá, 2016; Fernandes et al., 2017).

Estudos na região de Ilhabela, especialmente na área compreendida pelo Santuário Ecológico, são escassos. Fernandes et al. (2017) caracterizaram a área como local de alimentação e descanso de tartarugas marinhas, principalmente juvenis da espécie Chelonia mydas. Em seu levantamento, os pesquisadores relataram, adicionalmente, a existência de diversas modalidades de pesca, bem como grande fluxo de embarcações que passam em alta velocidade próximo à costa na área do Santuário.

Outros trabalhos realizados na área verificaram a existência de diferentes atividades de impacto 
direto à fauna, como pisoteio, alimentação de animais e coleta de exemplares marinhos (Sá, 2016); ou indiretos, como presença de resíduos nas praias (Treza, 2016).

Conforme ressaltado anteriormente, estudos realizados na área identificaram a inexistência de fiscalização e monitoramento, o que permite que as atividades acima descritas ocorram de forma indiscriminada, sendo muitas vezes controladas pelos próprios moradores ou turistas (obs. pessoal).

O SNUC, no entanto, não ignora em seu texto o tratamento que deve ser dado a áreas como o SEI,

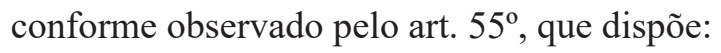

As unidades de conservação e áreas protegidas criadas com base em legislações anteriores e que não pertençam às categorias previstas nesta Lei serão reavaliadas, no todo ou em parte, no prazo de até dois anos, com o objetivo de definir sua destinação com base na categoria e função para as quais foram criadas, conforme disposto em Regulamento desta Lei (Brasil, 2000).

Há necessidade, portanto, de reavaliação e enquadramento do Santuário Ecológico de Ilhabela em uma das categorias contempladas pela Lei $n^{\circ} 9985 / 00$. Além da fiscalização das atividades na área, o fato de ser parte integrante do SNUC garante ao local o estabelecimento de um Plano de Manejo, por meio do qual seriam definidos, entre outros temas, o zoneamento e normas específicas para a área (Brasil, 2000).

O Santuário Ecológico de Ilhabela configura-se como área de ocorrência de tartarugas marinhas, além de rica biota marinha (Ilhabela, 2015a; Fernandes et al., 2017). Há, portanto, necessidade de criação de uma UC, bem como de elaboração de um Plano de Manejo que garantam a proteção desses organismos no local (Sorvilo, 2012; Ilhabela, 2015a; Sá, 2016; Treza, 2016; Fernandes et al., 2017).

Frente a isso, o presente artigo tem por objetivo discutir a atual situação do Santuário Ecológico de Ilhabela no âmbito de seu processo de recategorização e reforçar a importância deste processo para a manutenção da biodiversidade local, das atividades turísticas e da população que depende dos recursos marinhos como meio de sobrevivência ou de preservação de sua cultura.

\section{Ilhabela e a criação do Santuário Ecológico}

O município de Ilhabela $\left(23^{\circ} 46^{\prime} \mathrm{S}, 45^{\circ} 21^{\prime} \mathrm{W}\right)$ está localizado no Litoral Norte do Estado de São Paulo, a aproximadamente $213 \mathrm{~km}$ da capital paulista (APRECESP, 2015), e apresenta uma população estimada em 32.782 habitantes (IBGE, 2016a).

É o maior município arquipélago do litoral brasileiro e está separado do continente pelo Canal de São Sebastião, que possui aproximadamente 24 $\mathrm{km}$ de extensão e variações nas larguras das extremidades: 5,8 km a norte, $2 \mathrm{~km}$ ao centro e 6,4 na extremidade sul (Moellmann et al., 2001). Além da Ilha de São Sebastião, a maior e mais povoada do arquipélago, somam-se à área do município as Ilhas de Búzios e da Vitória, além de mais nove ilhotes (Silva, 2009) totalizando $347,5 \mathrm{~m}^{2}$ de área do município (IBGE, 2016b).

Morfologicamente, a Ilha de São Sebastião apresenta uma linha costeira bastante recortada, com pequenas baías delimitadas por esporões de serra e planícies flúvio-lagunares e flúvio-marinhas pouco desenvolvidas, onde se intercalam praias 
arenosas de pequena extensão (Hennies \& Hasui, 1977 apud Bendazzoli, 2014).

Segundo levantamento realizado em 2012, a população de Ilhabela mais que dobrou no período entre 1991-2010, apresentando taxa anual de crescimento de 3,12\% entre 2000 e 2010 (IP, 2012). No período de final de ano entre 2003 e 2004, aproximadamente 600 mil pessoas visitaram Ilhabela entre natal e ano novo (DERSA apud Gobbo, 2007), cenário que pode representar grande pressão antrópica para a fauna local (Gobbo, 2007).

O turismo em Ilhabela passou a se desenvolver com maior intensidade a partir da década de 1960 , representando atualmente a principal atividade econômica do município (Guimarães, 2006; Bendazzoli, 2014).

Devido à grande pressão turística no local, essa região enfrenta problemas como a especulação imobiliária da costa, ocupação desordenada e irregular, economia sazonal e impactos decorrentes do turismo na época de verão, sendo insuficientes tanto a infraestrutura instalada quanto a conservação ambiental (IP, 2012).

O município de Ilhabela, no entanto, está contemplado por duas UCs. O Parque Estadual de Ilhabela (PEIb), criado através do Decreto Estadual $n^{\circ} 9.414 / 77$, e a APA Marinha Litoral Norte, criada através do Decreto Estadual 53.525/08. O PEIb ocupa $84,3 \%$ do território terrestre e contempla suas doze ilhas, três ilhotes, três lajes e um parcel. A costa oceânica do Parque faz parte do Setor Maembipe da APA Marinha Litoral Norte havendo, portanto, sobreposição das duas UCs em algumas áreas (FF, 2015).

O Santuário Ecológico de Ilhabela foi criado através do Decreto $n^{\circ} 953$ de 30 de abril de 1992 e visava "a criação de um santuário ecológico no trecho mais castigado do canal, tendo por finalidade o repovoamento piscícola e sua regeneração como viveiro de animais marinhos" (Ilhabela, 1992a). Segundo o Decreto: "passa a ser considerada santuário ecológico municipal, a zona costeira com a respectiva coluna d'água numa largura de $50 \mathrm{~m}$ (cinquenta metros) e $1.500 \mathrm{~m}$ (mil e quinhentos metros) de extensão, ao longo da beira-mar, compreendida entre o Portinho e a Praia das Pedras Miúdas" (Figura 1).

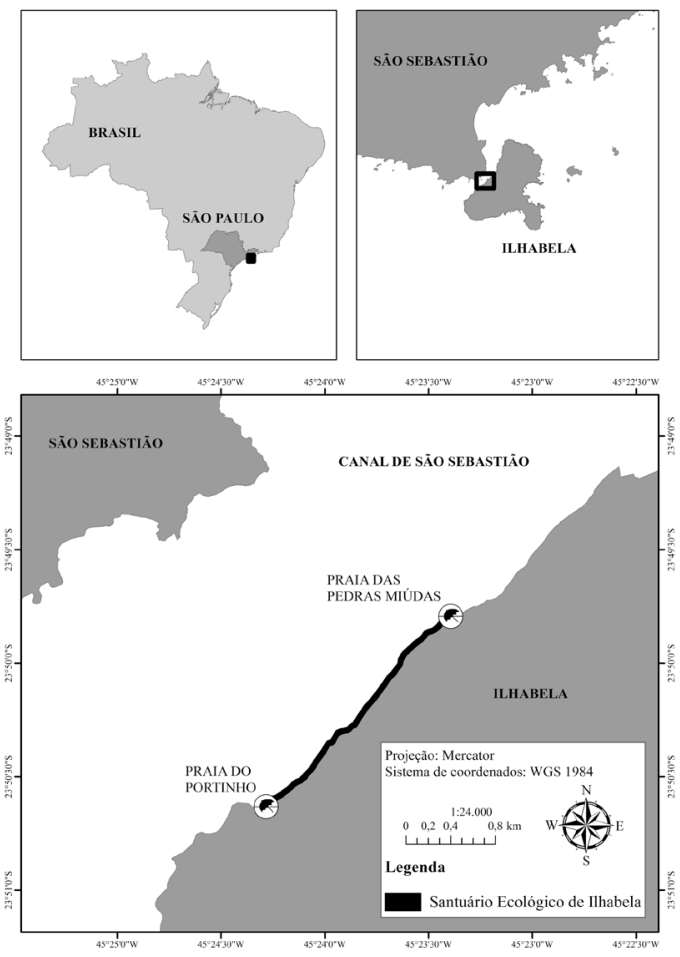

FIGURA 1 - Localização do Santuário Ecológico de Ilhabela.

Dentre as principais restrições associadas a esse Decreto, encontra-se a pesca submarina e a pesca e captura de organismos de qualquer natureza 
na coluna d'água, excetuando-se a pesca e coleta de natureza científica. Permaneceu permitida, apenas, a pesca que utiliza redes de cerco ou espera.

As problemáticas associadas ao uso e à presença humana em Ilhabela, mais especificamente na área do SEI, remetem à época da criação dessa área marinha protegida, como pode ser observado em trechos do Decreto de criação:

Considerando o processo de progradação marinha que resulta estar se acentuando a partir de 50m (cinquenta metros) da linha da costa [...];

Considerando a importância que representa nas metas preservacionistas, [...]; a criação de um santuário ecológico no trecho mais castigado do Canal, [...];

Considerando que em um passado não muito distante a inteira extensão do Canal juntamente às costas norte e nordeste foram conhecidas como pesqueiros fartos, em contrário à insignificância ictiológica que atualmente apresentam;

Considerando os estragos e os prejuízos causados durante anos seguidos à fauna aquática, pelo suceder de manchas de óleo e placas de hidrocarbonetos, advindos do derramamento de navios petroleiros a descarregar no Porto de São Sebastião [...] (Ilhabela, 1992a).

Assim, à altura do ano de 1992, o Canal de São Sebastião - e mais especificamente a atual área do Santuário Ecológico - já apresentava alterações em sua estrutura faunística e degradação ambiental devido a atividades antrópicas.

Ainda em 1992, o Decreto $n^{\circ} 953$ foi modificado pelo Decreto $\mathrm{n}^{\mathrm{0}} 1011$ que passa a permitir, por meio de seu Artigo $1^{\circ}$, a pesca artesanal “[...] assim entendida por meio de anzol, covos e redes de malha [...]" (Ilhabela, 1992b).

Ilhabela se trata de uma área utilizada por pescadores esportivos, atividade observada principalmente na região da Praia do Oscar ou nos píeres da Praia do Portinho (Sá, 2016), o que pode ter sido fator impulsionador para a modificação do recém-publicado Decreto à época.

Com a publicação do Plano de Manejo do Parque Estadual de Ilhabela, ficou estabelecido que o SEI seria abrangido pela parte marinha da Zona de Amortecimento do Parque. Segundo o SNUC (Brasil, 2000), a zona de amortecimento é definida como "o entorno de uma unidade de conservação, onde as atividades humanas estão sujeitas a normas e restrições especificas, com o propósito de minimizar os impactos negativos sobre a unidade". A Zona de Amortecimento não é considerada efetivamente como parte da área da UC, no entanto, trata-se de uma área que possui regras próprias, visando o estabelecimento de medidas de controle e a negociação do uso da área com as comunidades locais (Ganem, 2015). No Plano, o SEI está inserido no Setor de Conservação Marinha e no Setor Entorno das Ilhas. A área do Setor de Conservação Marinha coincide com a do SEI e se estende por mais 50m em direção à Prainha. Nele são permitidas atividades como pesca tradicional de subsistência com utilização de anzol, vara, covo e pequenas redes de espera (respeitando a Área de Interdição à Pesca Federal ao redor da Ilha das Cabras, localizada em frente à Praia das Pedras Miúdas), atividades de pesquisa científica, mergulho, turismo e esportes náuticos e sinalização. Dentre as atividades proibidas está a pesca em escala comercial, a captura de peixes e outros organismos marinhos para aquicultura/ aquariofilia, a pesca submarina, a introdução de espécies exóticas, disposição de água de lastro ou outras substâncias poluentes, bem como obras que provoquem a contaminação da água. Já no Setor Entorno de Ilhas, a proteção se estende por 200m ao redor da Ilha das Cabras, com limites abrangen- 
do a coluna d'água em direção à costa entre suas extremidades até o Santuário Ecológico, apresentando permissões e restrições similares ao Setor de Conservação Marinha (FF, 2015).

Frente a isso, a região do SEI não está completamente desassistida de proteção. O Plano de Manejo do PEIb sugere que as atividades nessas áreas sejam regulamentadas por meio do Conselho Gestor e do Plano de Manejo da APA Marinha Litoral Norte, cujo processo de criação foi iniciado mas encontra-se paralisado. No entanto, é importante ressaltar que o SNUC não estabeleceu sanções relacionadas ao descumprimento das normas estabelecidas pela Zona de Amortecimento, o que provoca questionamentos quanto à validade dessas regulamentações (Vitalli et al., 2009).

\section{A problemática atual do Santuário Ecológico de Ilhabela e potenciais benefícios advindos da criação de uma UC na área.}

Os impactos do turismo em regiões marinhas podem ser categorizados como ambientais, sociais e culturais; e podem ser associados à pressão populacional, à construções, disposição de resíduos, ou atividades como mergulho, fundeio, alimentação de animais, pisoteio de corais e demais organismos marinhos, pesca, entre outros (Harriott, 2002; Davenport \& Davenport, 2006).

Segundo Hall (2001), se mal planejadas, atividades turísticas podem gerar danos a ambientes naturais. Os dados levantados por Sá (2016) indicam que na área do SEI há distintas atividades, associadas principalmente ao turismo, que podem causar danos aos organismos marinhos, como, por exemplo, o trânsito de embarcações, que ameaça, entre outros animais, tartarugas marinhas e cetáceos que utilizam o Canal como área de passagem; fundeio em áreas indevidas (Milazzo et al., 2004); pisoteio e contato com animais marinhos, que prejudica organismos como corais, invertebrados e algas (Roman et al., 2007; Worachananant et al., 2008; Di Franco et al., 2009; Giglio et al., 2016); coleta de espécimes, que pode causar desequilíbrio das populações das espécies coletadas além de menores taxas de crescimento e de sucesso reprodutivo (Davenport \& Davenport, 2006; Lucas \& Smith, 2016); alimentação de animais, que pode causar dependência dessa alimentação suplementar, desenvolvimento de comportamento agressivo, competitividade entre espécies e habituação à presença humana (Milazzo et al., 2006; Milazzo, 2011; Dubois \& Fraser, 2013); pesca amadora e por meio de redes, podendo causar captura incidental (Peckham et al., 2007; Wallace et al., 2013); pesca predatória, com a utilização de arpão, entre outros.

É importante ressaltar que muitas das atividades que podem ser nocivas aos animais marinhos podem também ser perigosas aos seres humanos como, por exemplo, a presença de embarcações trafegando em alta velocidade em áreas muito próximas a banhistas; ancoragem em áreas delimitadas para mergulho; agressividade dos animais devido à alimentação; pisoteio de animais marinhos; presença de resíduos nas praias; entre outros. Assim, o ordenamento de atividades previsto com a criação de uma UC beneficiaria não apenas o ambiente marinho, mas também os turistas e a comunidade local da área.

Em termos de diversidade biológica, além da presença de espécies de tartarugas marinhas, a área também abriga peixes, aves, cetáceos e invertebrados marinhos, muitos dos quais estão ameaçados de 
extinção e que utilizam a área para alimentação, descanso, reprodução ou mesmo passagem. Ademais, a área do Santuário é classificada como berçário, ou seja, uma área segura para a postura de ovos e em que há maior chance de sobrevivência da prole (Ilhabela, 2015a).

Além das ameaças locais ao Santuário, está em andamento a tentativa de expansão do Porto de São Sebastião, que busca dobrar a área de operações, chegando a $800 \mathrm{mil} \mathrm{m}^{2}$. Caso seja efetivada, a obra trará uma série de consequências nocivas à área, como o aumento da poluição, ancoragem de navios, dragagem, além de pressão sobre os ecossistemas locais (Fagundes et al., 2014).

Apesar do SEI contar com uma possível proteção advinda da Zona de Amortecimento do PEIb, a criação de uma UC implicaria na elaboração de um Plano de Manejo específico para o local, garantindo um manejo mais direcionado para a região. Além do mais, o PEIb possui uma grande extensão a ser fiscalizada, principalmente em sua área terrestre, o que poderia comprometer o controle das atividades na região marinha da Zona de Amortecimento. Por fim, caso as permissões e restrições da Zona de Amortecimento sejam regulamentadas e colocadas em prática, não se deve perder de vista que a proteção estabelecida deve, de fato, ser suficiente para a manutenção dos processos e ecossistemas locais, assim como que, em caso de descumprimento das normas, sanções devem ser estipuladas.

A criação de uma UC pode promover oportunidades de geração de renda e desenvolvimento da economia local, principalmente à população diretamente atingida pela UC, conforme casos relatados por Reuchlin-Hugenholtz \& Mckenzie (2015) ao redor do mundo. A manutenção de um ambiente saudável e de beleza exuberante representa importante atrativo turístico, permitindo o fomento da economia local por meio de atividades como mergulho, ou ainda de outros ramos de prestação de serviços como hotéis, restaurantes, etc. As atividades turísticas podem gerar impactos positivos, tais como: benefícios às comunidades, por meio do aumento de suas receitas com atividades turísticas, e contribuições financeiras associadas à manutenção, planejamento e conscientização do público visitante com finalidade de conservação de ambientes marinhos (UNEP, 2002).

Seabra (2001) e Irving (2002) afirmam que a sustentabilidade da prática turística tem como base os princípios da preservação e conservação do patrimônio natural, da valorização do patrimônio histórico e cultural e do desenvolvimento econômico com equidade social, com a geração de benefícios para as comunidades dos destinos turísticos e sua participação efetiva. Desta forma, o turismo sustentável pode vir a ser uma grande oportunidade para envolver a comunidade local de Ilhabela nas atividades de fiscalização, monitoramento, e educação ambiental advindas da criação de uma UC, além de fonte de geração de renda.

Algumas categorias de UCs de Uso Sustentável, ou mesmo áreas provenientes do zoneamento em categorias de Proteção Integral (conforme estabelecido no Plano de Manejo), ao incorporarem ações de inclusão social e econômica das populações diretamente afetadas como objetivos inerentes à conservação, configuram-se como um decisivo avanço na concepção de áreas protegidas no Brasil. Por minimizarem os conflitos pelo uso do território, contribuem para a redução do maior obstáculo ao pleno funcionamento das áreas prote- 
gidas, ou seja, compatibilizam o interesse social e o preservacionista.

A criação de UCs de Uso Sustentável, por exemplo, torna legalizado o manejo de espécies animais (como os peixes e outros frutos do mar), desde que sejam conservadas as características do ecossistema. Se essas áreas forem adequadamente manejadas, uma produção sustentável pode ser garantida, dando oportunidade de renda à população local que já pratica, tradicionalmente, a pesca como forma de subsistência. Nelas, também estão sendo desenvolvidas importantes iniciativas de turismo, algumas delas realizadas em parceria com organizações não governamentais. Como exemplo, vale mencionar que a pesca é a atividade que mais gera renda e empregos para a população ribeirinha amazônica, e já chegou a representar $60 \%$ da renda gerada nos domicílios da Reserva de Desenvolvimento Sustentável Mamirauá, principalmente no que diz respeito ao manejo do pirarucu (Arapaimas gigas) (IDSM, 2010). Nesse sentido, segundo Irving (2009), os desafios associados à discussão do fenômeno turístico não mais se encontram no debate sobre incompatibilidades e riscos, mas sim na criação de alternativas criativas e inovadoras que levem em conta a variável local e os envolvidos como elementos centrais de planejamento.

No caso de Ilhabela, enquanto a criação da UC não ocorre, o município permanece crescendo e provocando o aumento da pressão sobre os recursos naturais advindos do turismo, da especulação imobiliária, da carência de infraestrutura, de obras e outros impactos atrelados à presença humana (IP, 2012; Ilhabela, 2015a).

\section{O processo de recategorização}

Os trabalhos realizados na área do Santuário Ecológico são escassos. Fernandes et al. (2015), Fernandes et al. (2017), Sá (2016) e Treza (2016) abordaram a problemática associada à recategorização do Santuário, uma vez que identificaram a área como local de alimentação e descanso de tartarugas marinhas, riqueza de recursos e de interações antrópicas.

Segundo o disposto no artigo $55^{\circ}$ do SNUC, o Santuário Ecológico de Ilhabela possui um atraso de aproximadamente 15 anos no cumprimento da legislação. Isto se deve ao fato de que o prazo máximo para reavaliação e recategorização das áreas protegidas, segundo o SNUC, era de no máximo dois anos desde a publicação da Lei, prazo expirado no ano de 2002.

Nos últimos anos, pesquisadores, organizações do terceiro setor e o próprio Município demonstraram interesse em retomar o processo de readequação da área através da realização de abaixo assinados (comum. pessoal) e apresentação de dados técnicos (Ilhabela, 2015a) que visavam a criação do Parque Natural Municipal Tartarugas de Ilhabela.

O processo, apesar de bem recebido pela maioria dos setores de Ilhabela, por vezes não foi bem visto por membros da comunidade de áreas próximas ao local de criação da área, que reclamaram direitos de manutenção de suas atividades tradicionais como, por exemplo, a pesca com rede e linha. Portanto, durante as audiências públicas realizadas, membros da comunidade próxima à futura área se posicionaram contra a criação da $\mathrm{UC}$, por acreditarem que esta poderia restringir suas atividades. 
A comunidade também questionou a escolha por uma categoria de UC de Proteção Integral ao invés de uma UC de Uso Sustentável, já que esta última possibilitaria a compatibilização de extração de recursos com a conservação da biodiversidade. Reivindicaram também a realização de diagnósticos participativos e maior participação da população local nas discussões sobre a criação da área.

Como possível alternativa para manter a proposta de criação de um Parque, foi discutida a utilização de instrumentos como Termos de Compromisso (TC). Essa medida está prevista no Art. $42 \S 2$ do SNUC e versa sobre o estabelecimento de normas e outras ações destinadas a compatibilizar a presença das populações com os objetivos da UC (Brasil, 2000). O documento que regulariza este instrumento, no entanto, foi publicado somente em 2012 por meio da Instrução Normativa do ICMBio $n^{\circ} 26$ e até hoje poucos foram os casos de utilização desta estratégia (Ribeiro \& Drummond, 2013). O TC pode ser utilizado, dentre outras circunstâncias, para regular a utilização dos recursos naturais existentes no interior de uma UC de Proteção Integral por comunidades tradicionais não residentes, mas usuárias desses recursos (Santilli, 2014), como seria o caso no Parque Natural Municipal em Ilhabela.

Segundo o Decreto $n^{\circ}$ 6.040/2007, que estabelece a Política Nacional de Desenvolvimento dos Povos e Comunidades Tradicionais, estes são definidos como grupos culturalmente diferenciados e que se reconhecem como tais, que possuem formas próprias de organização social, que ocupam e usam territórios e recursos naturais como condição para sua reprodução cultural, social, religiosa, ancestral e econômica, utilizando conhecimentos, inovações e práticas gerados e transmitidos pela tradição. Assim, a implantação de um TC estaria atrelada ao reconhecimento das famílias da região como comunidade tradicional, o que poderia ser feito por meio de Laudos Antropológico (Chagas, 2005).

Registros na literatura acerca de experiências na implantação de TCs em UCs de Proteção Integral têm mostrado importantes resultados na aceitação da área protegida por parte da comunidade local (Ribeiro \& Drummond, 2013), tornando-se uma alternativa que viabilizaria a manutenção das atividades tradicionais, garantindo maiores restrições a outros tipos de atividades prejudiciais ao meio, bem como a conservação da biodiversidade.

Quanto à categoria, "Parque" é a única que se refere especificamente a atividades associadas ao ecoturismo em sua definição (Menezes, 2014), o que a torna especialmente aplicável para Ilhabela, cuja receita municipal advém majoritariamente de atividades associadas ao turismo (Ilhabela, 2015b). Em muitas regiões, como no atual SEI, essas atividades apresentam desordenamento, podendo colocar em risco a saúde e bem-estar de turistas e das comunidades biológicas conforme descrito por Sá (2016). Outras alternativas, no entanto, podem e devem ser estudadas de forma a minimizar conflitos entre as partes interessadas e garantir a efetividade dos objetivos advindos da criação de uma área marinha protegida.

O histórico de criação de UCs no Brasil remete a processos conflituosos, que muitas vezes são conduzidos de forma centralizadora, burocrática e sem levar em consideração o contexto socioeconômico, passando a ser visto como um processo que impede o direito de existir e sobreviver das populações (Irving, 2014).

Atualmente o processo de recategorização do SEI se encontra paralisado e a sociedade permanece no aguardo de que as autoridades locais tomem ci- 
ência real do risco que correm a comunidade local, turistas e o meio ambiente marinho de Ilhabela, especialmente na região do Santuário Ecológico, caso medidas não forem tomadas no sentido da criação de uma UC no local e da implantação dos instrumentos presentes em seu texto.

\section{Possibilidades para o futuro}

No presente momento, o processo de readequação do Santuário Ecológico cabe principalmente ao Poder Público de Ilhabela, mas também aos ilhabelenses e outros setores interessados. Conforme dito anteriormente, a readequação das áreas criadas antes da publicação do SNUC é obrigatória e, segundo o Art. 40 do Decreto 4.340/2002, deverá ser feita "mediante ato normativo do mesmo nivel hierárquico que a criou", sendo este, no caso do Santuário Ecológico, encargo do Município.

A fim de evitar novos conflitos que possam impedir ou retardar o processo, sugere-se que os diversos setores da sociedade sejam convocados pelo Poder Público ou por setores interessados (como, por exemplo, organizações não governamentais) para formar um grupo que retome as discussões e debates sobre a criação de uma UC. Este processo deve ser participativo, de forma que todos os setores estejam representados, sejam ouvidos e se organizem para fortalecer os diálogos em direção à criação da área protegida.

Outra iniciativa de grande importância e valia seria a realização de palestras e oficinas com a temática de UCs a toda a população de Ilhabela, principalmente à população diretamente afetada quanto a possíveis restrições de atividades e uso de área em caso de criação da UC. É de suma impor- tância, no entanto, que essas atividades possuam conteúdo acessível e que sejam abordados temas desde a importância deste instrumento até os aspectos legais que dele fazem parte. Essa estratégia visa desmistificar o assunto e preparar a população para uma decisão mais segura e consciente quanto à criação de uma UC e todas as suas implicações. Esse espaço, além de informativo, poderia funcionar como uma oportunidade para que o Poder Público compreenda os olhares dos diversos setores sobre a questão e procure incorporá-los no processo, tornando a decisão participativa e aproximando a população dos interesses que dizem respeito a toda a sociedade.

Em um cenário ideal, esforços nesse sentido deveriam partir do órgão encarregado da realização do processo. Entretanto, a população também deve ter voz ativa e ser parte atuante e responsável pelas mudanças em seu entorno. Assim, deve também se organizar e estar à frente deste processo, garantindo um futuro melhor nos âmbitos ambiental, social e econômico de Ilhabela.

Espera-se que a presente publicação possa contribuir não somente como fonte de informação acerca da atual problemática do SEI, mas também despertar a reflexão sobre a recategorização de outras áreas ao SNUC em situação similar. Trata-se de uma oportunidade, portanto, para aumentar as possibilidades de conservação efetiva da biodiversidade e o avanço do Brasil frente à agenda internacional.

\section{Agradecimentos}

Os autores gostariam de agradecer à Dra. Luciana Yokoyama Xavier pela confecção da figura utilizada neste estudo. 


\section{Referências}

APRECESP - Associação das Prefeituras das Cidades Estâncias do Estado de São Paulo. Ilhabela. Disponível em: $<$ http://www.turpaulista.com.br/ilhabela $>$ Acesso em: jul. 2015.

Bendazzoli, C. O. Panorama da Ocupação Sambaquieira no Arquipélago de Ilhabela, SP. São Paulo, Tese (Doutorado em Arqueologia) - USP, 2014.

Brasil. Lei Federal No 9.985 de 18 de julho de 2000. Regulamenta o artigo 225 da Constituição Federal e institui o Sistema Nacional de Unidades de Conservação e da outras providências. Brasília: DOU de 19/07/2000.

Chagas, M. F. Estudos antropológicos nas "Comunidades remanescentes de quilombos": sinais que amplificam a luta por uma vida histórica, vida jurídica". In: Leite, I. B. (Org.). Laudos antropológicos em debate. Florianópolis: Co-edição NUER/ABA, 71-79, 2005.

Chape, S.; Harrison, J.; Spalding, M.; Lysenko, I. Measuring the extent and effectiveness of protected areas as an indicator for meeting global biodiversity targets. Philosophical Transactions of the Royal Society B: Biological Sciences, 360, 443-455, 2005. doi: 10.1098/rstb.2004.1592

Davenport, J.; Davenport, J. L. The impact of tourism and personal leisure transport on coastal environments: A review. Estuarine, Coastal and Shelf Science, 67(1), 280-292, 2006. doi: 10.1016/j.ecss.2005.11.026

Di Franco, A.; Milazzo, M.; Baiata, P.; Tomasello, A.; Chemello, R. Scuba diver behaviour and its effects on the biota of a Mediterranean marine protected area. Environmental Conservation, 36(1), 32-40, 2009. doi: 10.1017/ S0376892909005426

Diegues, A. C. S. A questão sociocultural nas áreas naturais protegidas. Debates Socioambientais, 3, 6-8, 1998.

Diegues, A. C. O mito moderno da natureza intocada. São Paulo: Hucitec, 3. ed., 2001.

Diegues, A. C. Comunidades Litorâneas e Unidades de Proteção Ambiental: convivência e conflitos, 2004. Disponível em: $<$ www.nupaub.fflch.usp.br/sites/nupaub.fflch.usp. br/files/color/guaraq.pdf.>. Acesso: jun. 2017.

Drummond, J. A.; Franco, J. L. A.; Oliveira, D. Uma análise sobre a história e a situação das Unidades de Conservação no Brasil. In: Ganem, R. S. (Org.). Conservação da biodiversidade: legislação e políticas públicas. 2011. Disponível em: $<$ http://bd.camara.gov.br/bd/handle/bdcamara/5444>. Acesso em: set. 2016.

Dubois, S., Fraser, D. A Framework to Evaluate Wildlife Feeding in Research, Wildlife Management, Tourism and Recreation. Animals, 3(4), 978-994, 2013. doi: 10.3390/ ani3040978

Dudley, N (Ed.). Guidelines for applying protected area management categories, 2008. Disponível em; $<$ www. cmsdata.iucn.org/downloads/guidelines_for_applying_protected_area_management_categories.pdf $>$. Acesso em: out. 2015.

Fagundes, L.; Carneiro, M. H.; Tomás, A. R. G.; Mucinhato, C. M. D.; Kolling, J. A.; Miranda, L. V.; Souza, M. R.; Zambeli, R. M.; Seckendorff, R. W. V.; Tutui, S. L. S. Atividade pesqueira e comunidades tradicionais de pescadores nos municípios de Ilhabela e São Sebastião, com ênfase no Canal de São Sebastião. Série Relatórios Técnicos, 53,1-41, 2014. Disponível em: $<\mathrm{ftp}: / / \mathrm{ftp}$. sp.gov. br/ftppesca/serreltec_53.pdf $>$.

Fernandes, A.; Bondioli, A. C. V.; Kienle, M. S.; Schiavetti, A. Ocurrence of adult resident hawksbill turtles (Eretmochelys imbricata) at Ilhabela, southeastern coast of Brazil. Herpetology Notes, 8, 115-117, 2015. Disponível em: $<$ http://biotaxa.org/hn/article/view/8707/12622>.

Fernandes, A.; Bondioli, A. C. V.; Solé, M.; Schiavatti, A. Seasonal Variation in the Behaviour of Sea Turtles at a Brazilian Foraging Area. Chelonian Conservation and Biology, 16(1), 93-102, 2017. doi: 10.2744/CCB-1200.1

FF - Fundação Florestal. Plano de Manejo Parque Estadual de Ilhabela, 2015. Disponível em:<http://fflorestal.sp.gov. br/files/2012/01/RESUMO-EXECUTIVO.pdf >. Acesso em: jun. 2017.

Ganem, R. S. Zonas de Amortecimento de Unidades de Conservação, 2015. Disponível em:<www2.camara.leg. br/a-camara/documentos-e-pesquisa/estudos-e-notas-tecnicas/areas-da-conle/tema14/2015-515-zonas-de-amorteci- 
mento-de-unidades-de-conservacao-roseli-ganem $>$. Acesso em: jun. 2017.

Giglio, V.; Luiz, O. J.; Schiavetti, A. Recreational Diver Behaviour and Contacts with Benthic Organisms in the Abrolhos National Marine Park. Environmental Management, 57(3), 637-648, 2016. doi: doi:10.1007/s00267015-0628-4

Gobbo, S. Padrão de distribuição e abundância de aves e mamíferos de médio e grande porte em Ilhabela, SP, Brasil. Piracicaba, Dissertação (Mestrado em Ecologia Aplicada) - ESALQ/USP, 2007

Guimarães, M. Análise do crescimento urbano de Ilhabela: seus reflexos e as perspectivas de planejamento para o município. São José dos Campos, Dissertação (Mestrado em Planejamento Urbano) - UNIVALE, 2006.

Hall, C. Trends in ocean and coastal tourism: the end of the last frontier? Ocean \& Coastal Management, 44, 9-10, 601618, 2001. doi: 10.1016/S0964-5691(01)00071-0

Harriott, V. J. Marine tourism impacts and their management on the Great Barrier Reef, 2002. Disponível em: <www.rrrc. org.au/wp-content/uploads/2014/04/Technical-Report-46. pdf $>$. Acesso em: set. 2016.

IBGE - Instituto Brasileiro de Geografia e Estatística. População. 2016a. Disponível em:<www.cidades.ibge.gov. $\mathrm{br} / \mathrm{xtras} /$ perfil.php?lang $=\&$ codmun $=352040 \&$ search $=$ sao-paulo|ilhabela>. Acesso em: jun. 2017.

IBGE - Instituto Brasileiro de Geografia e Estatística. Território e Ambiente. 2016b. Disponível em: < www.cidades. ibge.gov.br/xtras/perfil.php?lang=\&codmun=352040\&search=sao-paulo|ilhabela $>$. Acesso em: jun. 2017.

IDSM - Instituto de Desenvolvimento Sustentável Mamirauá. Plano de Gestão: Reserva de Desenvolvimento Sustentável Mamirauá - RDSM, 2010. Disponível em: $<\mathrm{ftp}: / /$ ftp.mct.gov.br/Biblioteca/44376-Plano_gestao_reserva_desenvolvimento_sustentavel_Mamiraua_Diagnostico.pdf $>$. Acesso em: jun.2017.

Ilhabela. Decreto Municipal no 953 de 30 de abril de 1992. Dispõe sobre a criação de um santuário ecológico em águas ilhabelenses, condena a pesca predatória, proíbe a pesca submarina numa extensão de 35 quilômetros ao longo da orla costeira, dispõe sobre medidas de proteção e criadouros de fauna marinha, prestigia a pesquisa científica e dá outras providências, 1992a.

Ilhabela. Decreto Municipal $n^{\circ} 1011$ de 1992. Introduz alteração do Decreto Municipal no 953 de 30 de abril de 1992, 1992 b.

Ilhabela. Estudo Técnico para Criação da Unidade de Conservação "Parque Natural Municipal Tartarugas de Ilhabela. 2015a. Disponível em:<www.ilhabela.sp.gov.br/ pdf/Estudos_Tecnicos_PNM_Tartarugas_de_Ilhabela.pdf $>$. Acesso em: out. 2015.

Ilhabela. Plano Municipal de Conservação e Recuperação da Mata Atlântica de Ilhabela, São Paulo, $2015 b$. Disponível em: <www.ilhabela.sp.gov.br/wp-content/ uploads/2016/02/PMMA_ILHABELA_2015.pdf > Acesso em: jun.2017.

IP - Instituto Pólis. Ilhabela - diagnóstico, 2012. Disponível em: <www.polis.org.br/publicacoes/diagnostico-urbano-socioambiental-e-programa-de-desenvolvimento-sustentavel-em-municipios-da-baixada-santista-e-litoral-norte-do-estado-de-sao-paulo-ilhabela/> Acesso em: ago. 2015.

Irving, M. A. Turismo, Ética e Educação Ambiental. In: Irving, M. A.; Azevedo, J. Turismo: o desafio da sustentabilidade. São Paulo: Futura, p. 17- 34, 2002.

Irving, M. A. Reinventando a reflexão sobre turismo de base comunitária: inovar é possível? In: Bartholo, R.; Sansolo, D. G.; Bursztyn, I. (Orgs.). Turismo de base comunitária: diversidade de olhares e experiências brasileiras, Rio de Janeiro: Letra e Imagem, p. 108-119, 2009.

Irving, M. A. Governança democrática e gestão participativa de áreas protegidas: um caminho sem volta para a conservação da biodiversidade no caso brasileiro. In: Bensusan, N.; Prates, A. P. (Orgs.). A Diversidade Cabe na Unidade? Áreas Protegidas do Brasil, Brasília: IEB Mil Folhas, p. 83-116, 2014.

ISA - Instituto Socioambiental. O que o governo Dilma fez e não fez pelas Unidades de Conservação? Disponível em: $<$ www.socioambiental.org/pt-br/noticias-socioambientais/o-que-o-governo-dilma-fez-e-nao-fez-pelas-unidades-de-conservacao>. Acesso em: nov. 2016. 
Lucas, B. J.; Smith, J. R. Alterations in human visitation patterns and behaviours in southern California rocky intertidal ecosystems over two-decades following increased management efforts. Ocean \& Coastal Management, 121, 128-140, 2016. doi: 10.1016/j.ocecoaman.2015.12.014

Medeiros, R. Evolução das tipologias e categorias de áreas protegidas no Brasil. Ambiente \& Sociedade, 9(1), 41-64, 2006.

Medeiros, R.; Irving, M. A.; Garay, I. A Proteção da Natureza no Brasil: evolução e conflitos de um modelo em construção. RDE - Revista de Desenvolvimento Econômico, 9, 83-93, 2004. Disponível em:< www.revistas.unifacs.br/ index.php/rde/article/view/115/119>.

Medeiros, R.; Young, C. E. F. Contribuição das unidades de conservação brasileiras para a economia nacional: Relatório Final, 2011. Disponível em: <mma.gov.br/estruturas/240/_arquivos/relatorio_final_contribuio_uc_para_a_economia_nacional_reduzido_240.pdf $>$. Acesso em: nov. 2016 .

Menezes. P. C. “Conhecer para Conservar" - um rápido olhar histórico seguido da verdadeira motivação do ecoturismo para todos que trabalham com conservação. In: Bensusan, N.; Prates, A. P. (Orgs). A Diversidade Cabe na Unidade? Áreas Protegidas do Brasil, Brasília: IEB Mil Folhas, p. 83-116, 2014.

Milazzo, M. Evaluation of a behavioural response of Mediterranean coastal fishes to novel recreational feeding situation. Environmental Biology of Fishes, 91, 127-132, 2011. doi: 0.1007/s10641-011-9784-4

Milazzo, M.; Badalamenti, F.; Ceccherelli, G.; Chemello, R. Boat anchoring on Posidonia oceanica beds in a marine protected area (Italy, western Mediterranean) effect of anchor types in different anchoring stages. Journal of Experimental Marine Biology and Ecology, 299, 51-62, 2004. doi:10.1016/j.jembe.2003.09.003

Milazzo, M.; Anastasi, I.; Willis, T. J. Recreational fish feeding affects coastal fish behaviour and increases frequency of predation on damselfish Chromis chromis nests. Marine Ecology Progress Series, 310, 165-172, 2006. doi: 10.3354/ meps 310165

MMA-Ministério do Meio Ambiente. A Convenção sobre a
Diversidade Biológica $-C D B, 2000$. Disponível em: $<\mathrm{http}: / /$ www.mma.gov.br/estruturas/sbf_dpg/_arquivos/cdbport. pdf $>$. Acesso em: fev. 2016.

MMA - Ministério do Meio Ambiente. SNUC - Sistema Nacional de Unidades de Conservação da Natureza: Lei $n^{\circ}$ 9.985, de 18 de julho de 2000; Decreto $n^{\circ} 4.340$, de 22 de agosto de 2002; Decreto $n^{\circ}$ 5.746, de 5 de abril de 2006. Plano Estratégico Nacional de Areas Protegidas: Decreto $n^{\circ}$ 5.758, de 13 de abril de 2006, 2011a. Brasília: MMA, 76 p

MMA - Ministério do Meio Ambiente. Dez anos do Sistema Nacional de Unidades de Conservação da Natureza: lições do passado, realizações presentes e perspectivas para o futuro, 2011b. Disponível em:<www.mma.gov.br/estruturas/240/_publicacao/240_publicacao06072011055602. pdf>. Acesso em: jun. 2017.

MMA - Ministério do Meio Ambiente. Resolução CONA$B I O n^{\circ} 06$ de 03 de setembro de 2013. Dispõe sobre Metas Nacionais de Biodiversidade para 2020. Disponível em:< http://bibspi.planejamento.gov.br/handle/iditem/371>. Acesso em: set.2016.

Moellmann, A. M.; Corbisier, T. N.; Curvelo, R. R. Variação espacial entre verão e inverno da meiofauna do Canal de São Sebastião - SP. Revista Brasileira Oceanográfica, 49 (1/2), 75-85, 2001. Disponível em:<www.scielo.br/pdf/ rboce/v49n1-2/07.pdf>

Padovan, M. P. Formulação de parâmetros e de um procedimento para certificação do manejo de Unidades de Conservação. In: Anais do $3^{\circ}$ Congresso Brasileiro de Unidades de Conservação. Fortaleza, 2002.

Peckham, S. H.; Diaz, D. M.; Walli, A.; Ruiz, G.; Crowder, L. B.; Nichols, W. J. Small-scale Fisheries Bycatch Jeopardizes Endangered Pacific Loggerhead Turtles. Plos One, 10(e1041), 2007. doi:10.1371/journal.pone.0001041

Prates, A. P. Oceanos, a nova fronteira de conservação no Brasil? In: Bensusan, N.; Prates, A. P. (Orgs). A Diversidade Cabe na Unidade? Áreas Protegidas do Brasil, Brasília: IEB Mil Folhas, p. 121-151, 2014.

Prates, A. P.; Sousa, N. O. M. Panorama Geral das Áreas Protegidas no Brasil: desafios para o cumprimento da Meta 11 de Aichi. In: Bensusan, N., Prates, A. P. (Orgs). A Diversidade Cabe na Unidade? Áreas Protegidas do Brasil, 
Brasília: IEB Mil Folhas, p. 83-116, 2014.

Reuchlin-Hugenholtz, E.; Mckenzie, E. Marine protected areas: Smart investments in ocean health, 2015. Disponível em: <www.ocean.panda.org/media/WWF_Marine_Protected_Areas_LR_SP.pdf $>$. Acesso: jun. $201 \overline{7}$.

Ribeiro, B. G.; Drummond, M. A. O Termo de Compromisso como Ferramenta para a Gestão de Conflitos em Unidades de Conservação. In: Anais do VI Seminário Brasileiro sobre Áreas Protegidas e Inclusão Social. Belo Horizonte, 15-20 de set., 2013.

Roman, G. S. J.; Dearden, P. Application of Zoning and "Limits of Acceptable Change" to Manage Snorkelling Tourism. Environmental Management, 39, 819-830, 2007. doi: 10.1007/s00267-006-0145-6

Sá, M. P. G. Usos e ameaças às tartarugas marinhas no Santuário Ecológico de Ilhabela (SP): subsídios para a readequação de uma área marinha protegida. Diadema, Dissertação (Mestrado em Análise Ambiental Integrada) - UNIFESP, 2016.

Santilli, J. Áreas protegidas e direitos de povos e comunidades tradicionais. In: Bensusan, N.; Prates, A. P. (Org.). A Diversidade Cabe na Unidade? Áreas Protegidas do Brasil, Brasília: IEB Mil Folhas, p. 83-116, 2014.

Schiavetti, A.; Manz, J.; Santos, C. Z.; Magro, T. C.; Pagani, M. I. Marine Protected Areas in Brazil: an ecological approach regarding the large marine ecosystems. Ocean \& Coastal Management, 76, 96-104, 2013. doi: 10.1016/j. ocecoaman.2013.02.003

Seabra, G. F. Ecos do Turismo: turismo ecológico em áreas protegidas. Campinas: Papirus, 2001.

Silva, C. D. R. Cidade e Natureza. Mercado imobiliário, turismo e desenvolvimento urbano em Ilhabela. São Paulo, Dissertação (Mestrado em Arquitetura e Urbanismo) - USP, 2009.
Sorvilo, R. Estrutura e Diversidade da Comunidade Ictiofaunística da Ilha das Cabras, Ilhabela, São Paulo, pelo método de vídeo-transecto. São Paulo, Dissertação (Mestrado em Aquicultura e Pesca) - IP, 2012.

Treza. C. C. Potencial impacto do lixo nas áreas de alimentação de tartarugas marinhas em Ilhabela-SP. São Paulo, Monografia (Bacharelado em Ciências Biológicas) - CUSC, 2016.

UNEP - United Nations Environment Programme. Ecotourism: Principles, Practices \& Policies for Sustainability, 2002. Disponível em:<wedocs.unep.org/bitstream/ handle/20.500.11822/9045/-Ecotourism_\%20\%20Principles, $\% 20$ Practices $\% 20$ and $\% 20$ Policies $\% 20$ for $\% 20$ Sustainability-2002518.pdf?sequence $=2>$. Acesso em: nov.2016.

Vitalli, P. L.; Zakia, M. J. B.; Durigan, G. Considerações sobre a legislação correlata à zona-tampão de Unidades de Conservação no Brasil. Ambiente e Sociedade, 6(1), 2009. doi: 10.1590/S1414-753X2009000100006

Wallace, B. P.; Kot, C. Y.; DiMatteo, A. D.; Lee, T.; Crowder, L. B.; Lewison, R. L. Impacts of fisheries bycatch on marine turtle populations worldwide: toward conservation and research priorities. Ecosphere, 4(3), 40, 2013. doi: 10.1890/ES12-00388.1

Weigand Junior, R.; Silva, D. C.; Oliveira e Silva, D. Metas de Aichi: situação atual no Brasil, 2011. Disponível em: $<$ http://www.wwf.org.br/informacoes/?uNewsID=29462>. Acesso em: jun. 2017.

Worachananant, S.; Carter, R.W.; Hockings, M.; Reopanichkul, P. Managing the Impacts of SCUBA Divers on Thailand's Coral Reefs. Journal of Sustainable Tourism, 16(6), 645-663, 2008. doi: 10.2167/jost771.0 